\title{
Usability of Mobile Health Application for Individuals with Type 2 Diabetes Mellitus and Clinicians
}

\author{
Eren Timurtas (1), Mine Gulden Polat \\ Marmara University, Faculty of Health Sciences, Department of Physiotherapy and Rehabilitation, Istanbul, Turkey
}

Correspondence Author: Eren Timurtas

E-mail: fzteren@gmail.com

Received: $01.08 .2019 \quad$ Accepted: 30.09 .2019

\begin{abstract}
Objective: Usability of technological devices is an important and relevant construct as mobile technologies are increasingly used to deliver healthcare products. Most accessible devices are smartphone and smartwatch but information on their usability is scarce. The aim of this study is to compare the usability of smartphone and smartwatch devices in delivering an exercise platform to individuals with Type 2 Diabetes Mellitus (T2DM) among two focus groups: individuals with T2DM and clinicians.

Methods: A total of 40 individuals with T2DM (focus group 1) and 20 clinicians (focus group 2) were recruited to use the platforms one week. Each focus group was randomly divided into: smartphone and smartwatch groups. Each participant was provided with a practice trial for a week before data collection. Usability of both devices was measured with System Usability Scale (SUS). Student t-test was used to compare the total and subscale scores of SUS between two devices in each focus group.

Results: In focus group 1 and 2, the mean total scores of SUS were slightly higher in smartphone group $(88,75 \pm 9,34$ and 86,75 $\pm 8,68)$ than smartwatch group $(87,87 \pm 7.56$ and $82,35 \pm 6,59)$ respectively. When compared to individual items, three items were statistically significant in focus group 1 and one in focus group $2(p \leq 0.05)$.

Conclusion:This study demonstrates a high usability (SUS score>80,8) for both smartphone and smartwatch devices in individuals with T2DM and clinicians. When compared between devices for two groups, exercise platform delivered through smartphone performed better on usability than smartwatch for both individuals with T2DM and clinicians.
\end{abstract}

Keywords: Type 2 Diabetes Mellitus, Mobile Health, Smartphone, Technology

\section{INTRODUCTION}

Type 2 Diabetes Mellitus (T2DM) is one of the most prevalent chronic health conditions around the world and costs large burden to the health care system particularly for the middleincome countries with already constrained resources [1]. The main goal of management for individuals with T2DM is to maintain blood glucose levels within normal limits through optimal use of medications combined with physical activity (PA) [2]. PA is an important aspect in achieving optimal glycemic control. The extent to which a person participates in PA is directly influenced by his or her preferences that are under self-control [3]. However, approximately $60 \%$ of individuals with T2DM fail to meet the PA guidelines [4], which are, at least 150 minutes of moderate to vigorous aerobic exercise and at least 2 sessions per week of resistance exercise [3]. Currently, there are several technological choices at disposal to these population so as to meet the PA guidelines [5].

There are many technological devices commercially available to help individuals with T2DM to meet the PA guidelines and maintain good health [6]. Exercise applications are most commonly delivered through mobile devices such as smartphone and smartwatch [7]. Smartphone applications typically allow an individual to monitor his/her PA level by providing real-time feedback and also generate a personalized exercise program tailored to individual needs [8]. Smartwatch applications additionally can monitor some physiological parameters such as heart rate and blood pressure through sensors [5]. Given these qualifications, smartphone and smartwatch have been shown to be efficacious to improve PA levels and reduce sedentary behaviour in individuals with T2DM [6-8]. However, in order to maximize the benefits from these devices, it is critical to ensure that the people use all the features of these technologies on regular basis and for sustained duration of time.

While there are several studies that have evaluated the clinical efficacy of the mobile applications in T2DM [9], there are a very few studies that have reported any information about the usability and acceptability of mobile applications 
[10]. Furthermore, around 95\% studies that involve use of smartphone for health applications lack any information on usability [11]. Of the remaining, even fewer studies have obtained feedback from the users but missed information or feedback from the clinicians [12]. Only one study has investigated the usability of smartwatch applications in self management for individuals with T2DM [13]. Existing studies on smartwatch usability was only patient based and was not custom applications [14].

From users' perspective, usability of these applications includes efficiency, effectiveness, and satisfaction so as to achieve a specified goal $[15,16]$. Usability is considered an essential aspect in the development process for an application [17] [18] as it facilitates the extent to which these applications will be adopted by an individual [19]. Usability reports are also used to guide the upgrades in these applications [20]. Moreover, a usability analysis of these applications will meet the needs of the users and experts and will create applications that could be used in future research in PA and health promotion [21].

While smartphones and smartwatches are reported to be widely used to monitor and improve PA in T2DM, there continue to be a gap in the literature on the comparative effectiveness of these devices in terms of their usability [22]. Brooke's usability definition used [23] in this study refers to whether users complete a task using the applications, to see the level of resource consumed in performing a task and to understand user reactions to use of the applications. Furthermore, to assess usability from a clinicians' perspective can provide insights into redesign of the application and its content validity. Therefore, this study is an important contribution to the body of knowledge on usability of exercise platforms for individuals with T2DM.

The global aim of this project is to contribute evidence towards the barriers and facilitators of technology adoption to maintain PA in T2DM. The specific objective is to compare usability of smartphone and smartwatch devices in delivering an exercise platform to individuals with T2DM in two focus groups (individuals with T2DM and clinicians)

\section{METHODS}

\subsection{Design}

The study is a cross section analysis of data obtained from RCT designed to test comparative effectiveness of exercise intervention delivered through smartphone and smartwatch for glycemic control in individuals with T2DM. Other exploratory outcomes included usability of these devices in delivering the interventions. The current study is to analysis and present the findings of usability of these devices. The trial was carried out at the Fatih Sultan Mehmet Hospital Diabetes and Obesity Center in Istanbul, Turkey. The assessments were carried out between January and February 2018. The ethical approval for the study was obtained from Marmara University Clinical Research Ethics Committee, Istanbul, Turkey.

\subsection{Participants}

Participants were included in focus group 1 if they were 1) diagnosed with T2DM 2) at between the age of 18 to 65 years old and 3) free from any diagnosis of cognitive impairments, neurological and orthopedic disorders. Focus group 2 included if they 1) were physiotherapists with minimum master degree, 2) possessed at least 3 years of clinical experience in either public or private settings and have been currently working with patient with T2DM. All participants provided a written informed consent prior to their participation. Data on a total of all the 40 individuals with T2DM and 20 physiotherapists as clinicians was available.

\subsection{Randomization}

40 individuals with T2DM (focus group 1) and 20 physiotherapists (focus group 2) were randomly assigned (1:1 ratio) into two groups (smartphone and smartwatch) such that the groups were matched for age, sex, and education.

\subsection{Measures}

System Usability Scale (SUS) was one of the exploratory outcomes in the trial [24]. SUS is a 10 item self-report questionnaire to measure usability of software and hardware products. Each item is scored on a 5-point Likert scale from 1 (strongly disagree) to 5 (strongly agree). Of the 10 items, item no. 1, 3, 5, 7 and 9 are positively worded (higher score represents strongly agree) and item no. 2, 4, 6,8 and 10 are negatively worded (higher score represents strongly disagree). SUS is validated in Turkish language [25] and widely used to obtain users' [24] and clinicians' [26] perception on technology. To calculate total score for odd numbered items, the individual item score is subtracted from 5 which is the maximum possible score on each item. These scores are added to obtain a total subscale score for odd numbered items. For even numbered items, individual scores are subtracted from 1 which is the minimum score possible for each item. These scores are added to get subscale score for even numbered items. The total score for SUS is a sum of subscale score for odd and even numbered items multiplied by 2.5 . The standardized score ranges from 0 to 100 where 100 represents higher usability [26].

\subsection{Procedures}

Diabetex online exercise platform (DIABETEX; www. diabetex.com) has been developed by research team at Department of Physiotherapy and Rehabilitation, Marmara University that can be delivered either via a smartphone or smartwatch. Diabetex is an online platform that includes exercise types and parameters. It allows clinicians to monitor exercise performance and modify his/her exercise program accordingly. There is possibility for the clinicians to send push notification to patients based on their performance and progress. The exercise platform is compatible with both Android and IOS version. Figure 1 shows two images for 
each of devices displaying the exercise platform. The devices provide an individually tailored exercise plan and has capacity to track as well as provide feedback. At the onset when the devices were given to the participants, they received training session for approximately 45 minutes. The session included practice with a full set of the exercise sessions as prescribed for individual. The participants than took the devices home for a week to test and use all features of the platform. They were required to complete at least 3 exercise sessions during that period. After a week individuals with Type 2DM and clinicians completed SUS online.

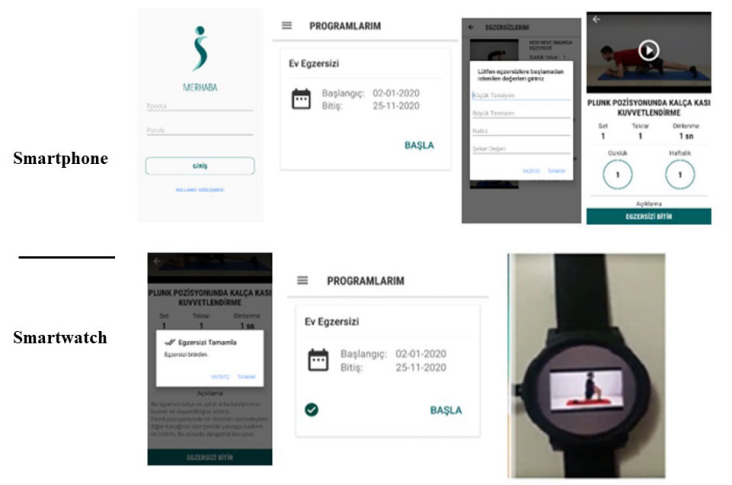

Figure 1: Screenshots of Diabatex Exercise Platform Delivered through Smartphone and Smartwatch

\subsection{Statistical analysis}

Each item was tested for normality using KolmogorovSmirnov test. The Student t-test was performed for each item between the two groups. The critical cut-off value for statistically significance was set at $p \leq 0.05$ [27] . Statistical analysis was carried out with IBM SPSS Statistics, version 22.0 (IBM Corporation, Armonk, New York, USA).

\section{RESULTS}

The characteristics of individuals with T2DM and clinicians are shown in Table 1. The variables of age, education, and diagnosis for individuals with T2DM only, are shown as mean and SD. Mean is an inaccurate reflection of personal scores when the response categories are ordinal in nature. Therefore, median values for each of the 10 item on SUS are shown in Table 2. In focus group 1, the mean (SD) total score on SUS were $88,75(9,34)$ for smartphone group and $87,87(7,56)$ for smartwatch group. In focus group 2 , these results were $86,75(8,68)$ for smartphone group and 82,35 $(6,59)$ for smartwatch group. Figure 2 shows the graphical representation of the mean scores for focus group 1, while figure 3 demonstrates for focus group 2 . In focus group 1 , three items revealed statistically significant differences between two groups including item \#3 (I thought this app was easy to use), \#4 (I think that I would need assistance to be able to use this app) and \#10 (I needed to learn a lot of things before I could get going with this app). In all three items, the usability of smartphone was expressed as better than smartwatch. In focus group 2, only differences were in item \#10 between the groups where smartphone revealed a better score than smartwatch.

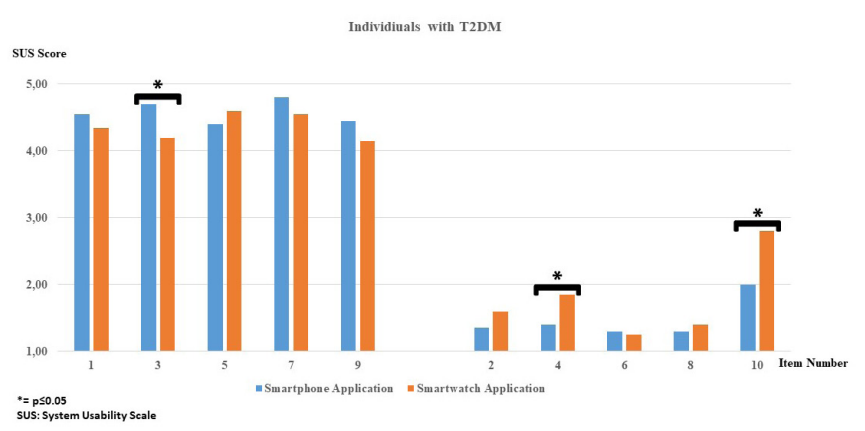

Figure 2: The mean scores of each item for individuals with T2DM

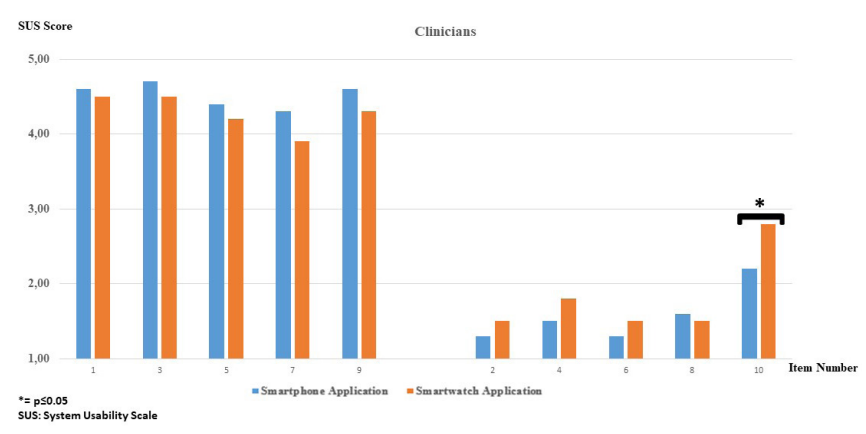

Figure 3: The mean scores of each item for clinicians

Table 1: Demographic characterictics of the individuals with T2DM and clinicians

\begin{tabular}{|c|c|c|}
\hline $\begin{array}{l}\text { Characteristics of the individuals } \\
\text { with T2DM }\end{array}$ & $\begin{array}{l}\text { Smartphone } \\
\text { application } \\
\text { Mean (SD) / N }\end{array}$ & $\begin{array}{l}\text { Smartwatch } \\
\text { application } \\
\text { Mean (SD) / N }\end{array}$ \\
\hline Age (years) & $46,1(8,9)$ & $46,1(8,8)$ \\
\hline Diagnosis (years) & $9,5(3,1)$ & $9,9(2,8)$ \\
\hline \multicolumn{3}{|l|}{ Education } \\
\hline Graduate & 2 & 2 \\
\hline Bachelor & 7 & 8 \\
\hline High school & 6 & 5 \\
\hline Secondary School & 5 & 5 \\
\hline \multicolumn{3}{|l|}{ Mobile phone (operating system) } \\
\hline Android & 12 & 20 \\
\hline IOS & 8 & - \\
\hline \multicolumn{3}{|l|}{ Characteristics of the clinicians } \\
\hline Age (years) & $37,3(12,3)$ & $38,9(12,1)$ \\
\hline \multicolumn{3}{|l|}{ Education } \\
\hline Doctoral degree & 6 & 6 \\
\hline Master degreee & 4 & 4 \\
\hline \multicolumn{3}{|l|}{ Mobile phone (operating system) } \\
\hline Android & 7 & 10 \\
\hline IOS & 3 & - \\
\hline
\end{tabular}

$S D$ : Standard Deviation 
Table 2: Comparison of SUS scores between smartphone $\mathrm{v} / \mathrm{s}$ smartwatch for individuals with T2DM and clinicians

\begin{tabular}{|c|c|c|c|c|c|c|}
\hline \multirow[b]{2}{*}{$\begin{array}{l}\text { Groups } \\
\text { SUS score Item score }\end{array}$} & \multicolumn{3}{|c|}{ Individuals with T2DM } & \multicolumn{3}{|c|}{ Clinicians } \\
\hline & $\begin{array}{l}\text { SP } \\
\text { Median } \\
\text { (min-max) }\end{array}$ & $\begin{array}{l}\text { SW Median } \\
\text { (min-max) }\end{array}$ & p* & $\begin{array}{l}\text { SP Median } \\
\text { (min-max) }\end{array}$ & $\begin{array}{l}\text { SW Median } \\
\text { (min-max) }\end{array}$ & p* \\
\hline \multicolumn{7}{|l|}{ Items of SUS (higher score represents strongly agree) } \\
\hline I think that I would like to use this app frequently. (item \#1) & $5(3-5)$ & $5(2-5)$ & 0,31 & $5(1-5)$ & $(1-5) 5$ & 0,36 \\
\hline I thought this app was easy to use. (item \#3) & $5(3-5)$ & $4(2-5)$ & $0,01^{*}$ & $5(1-5)$ & $5(1-5)$ & 0,56 \\
\hline I found the various functions in this app were well integrated. (item \#5) & $5(2-5)$ & $5(2-5)$ & 0,08 & $4(1-5)$ & $4(1-5)$ & 0,20 \\
\hline $\begin{array}{l}\text { I would imagine that most people would learn to use this app very quickly. } \\
\text { (item \#7) }\end{array}$ & $5(2-5)$ & $5(2-5)$ & 0,10 & $4(1-5)$ & $4(1-5)$ & 0,57 \\
\hline I felt very confident using this app. (item \#9) & $5(2-5)$ & $4(1-5)$ & 0,19 & $5(1-5)$ & $4(1-5)$ & 0,07 \\
\hline \multicolumn{7}{|l|}{ Items of SUS (higher score represents strongly disagree) } \\
\hline I found this app unnecessarily complex. (item \#2) & $1(1-5)$ & $1(1-5)$ & 0,06 & $1(1-5)$ & $1(1-5)$ & 0,29 \\
\hline I think that I would need assistance to be able to use this app. (item \#4) & $1(1-5)$ & $2(1-5)$ & $0,01 *$ & $1(1-5)$ & $1(1-5)$ & 0,71 \\
\hline I thought there was too much inconsistency in this app. (item \#6) & $1(1-5)$ & $1(1-5)$ & 0,44 & $1(1-5)$ & $1(1-5)$ & 0,56 \\
\hline I found this app very cumber some awkward to use. (item \#8) & $1(1-5)$ & $1(1-5)$ & 0,18 & $1(1-5)$ & $1(1-5)$ & 0,63 \\
\hline $\begin{array}{l}\text { I needed to learn a lot of things before I could get going with this app. (item } \\
\# 10 \text { ) }\end{array}$ & $2(1-5)$ & $3(1-5)$ & $0,01^{*}$ & $2(1-5)$ & $3(1-5)$ & $0,03^{*}$ \\
\hline $\begin{array}{l}\text { Total score mean } \\
\text { (SD) }\end{array}$ & $88,75(9,34)$ & $87,87(7,56)$ & 0,21 & $\begin{array}{l}86,75 \\
(8,68)\end{array}$ & $82,35(6,59)$ & 0,27 \\
\hline
\end{tabular}

* $p \leq 0.05$ app: application, SD: Standard Deviation, SP:Smartphone, SUS: System Usability Scale, SW:Smartwatch

\section{DISCUSSION}

The aims of this study was to understand the usability of Diabetex exercise platform on smartphone and smartwatch in individuals with T2DM and clinician. Moreover, objective of this research was to compare usability of Diabetex exercise platform designed for individuals with T2DM to provide exercise and physical activity tracking on smartphone and smartwatch devices. This study has demonstrated an excellent usability (SUS SCORE>80,8) [28] for Diabetex when delivered using smartphone and smartwatch devices in individuals with T2DM and clinicians. The comparison of two devices for the usage of platform showed that Diabetex exercise platform when presented through smartphone showed better usability than smartwatch for both individuals with T2DM and clinicians. The analysis of individual items revealed that for the individuals with T2DM these differences was due to technical support provided to use smartwatch that was not offered for smartphone. The participant also needed assistance to use smartwatch than smartphone and took longer time to learn all features of smartwatch than smartphone. Clinicians reported same statement with patient which to learn a lot of things before this application in smartwatch to compare with smartphone.

The results of this study demonstrated that participants encountered some difficulties to use the smartwatch that is due to the advance technically features of smartwatch in comparison to smartphone. Technical problems that battery technology as well as cultural barriers are emphasized in other study that evaluated smartwatch devices used for rehabilitation [29]. In another qualitative studies that included evaluation of wearable technology for women with breast cancer showed negative preference for uptake of technology for physical activity [30]. The participant in this study did not report any negative preference for
Diabetex exercise platform. In fact, the participants reported satisfaction with two delivery methods that they can choose.

Usability problems are appraised as a feature that can lead mobile health to failure and inclusion of clinicians in development process has not been so common [31]. This research team who developed our application was included software engineers, clinicians and patients.

According to recent report, more than half of mobile device users had downloaded one or more mobile health apps but approximately half of those users do not use the applications [32]. This study show that usability of diabetes smartphone applications has limited user compatibility. In another study about mobile applications developed for T2DM, there was limited information on about usability of the mobile devices [33]. A review about mobile exercise health application stated technical problems and application malfunctions. Moreover, most applications developed are usually peer reviewed by professionals or clinicians [34]. Up to now, there are fewer number of studies that focus on usability for delivery of health services using mobile technologies such as smartphone [35] or wearable [36] technology. This study focused on difference in usability of these devices on perception individuals with T2DM as well as clinicians.

\section{CONCLUSION}

The current study showed that Diabetex exercise platform was seen excellent usability by individuals with T2DM and clinicians. Furthermore, usability of Diabetex exercise platform when delivered through smartphone has higher acceptability than delivered through smartwatch. An understanding of usability smartphone and smartwatch for 
exercise application in individuals with T2DM and clinician will shed light on mobile app developers. The findings of this study have greater future implications in delivery of exercise interventions.

\section{Limitations}

The study was secondary analysis of data and was not designed to test the usability as the main outcome. There was lack of guidelines on the duration to get familiar with the online platform before administering SUS. The team thought one week would suffice as an acceptable time frame for people to be familiar with the platform. There was lack of data on the frequency of platform usage for individuals with T2DM.

\section{Acknowledgement}

This study supported by the Scientific and Technological Research Council of Turkey (TUBITAK) with the project number 1059B141800431. We are sincerely grateful to TUBITAK 2214-A-2018/1.

\section{REFERENCES}

[1] Cho N, Shaw J, Karuranga S, Huang Y, da Rocha Fernandes J, Ohlrogge A, Malanda B: IDF Diabetes Atlas: Global estimates of diabetes prevalence for 2017 and projections for 2045 . Diabetes Res Clin Pract 2018; 138:271-281.

[2] Davies MJ, D’Alessio DA, Fradkin J, Kernan WN, Mathieu C, Mingrone G, Rossing P, Tsapas A, Wexler DJ, Buse JB: Management of hyperglycaemia in type 2 diabetes, 2018. A consensus report by the American Diabetes Association (ADA) and the European Association for the Study of Diabetes (EASD). Diabetologia 2018; 61:2461-2498.

[3] Colberg SR, Sigal RJ, Yardley JE, Riddell MC, Dunstan DW, Dempsey PC, Horton ES, Castorino K, Tate DF: Physical activity/ exercise and diabetes: a position statement of the American Diabetes Association. Diabetes care 2016; 39:2065-2079.

[4] Morrato EH, Hill JO, Wyatt HR, Ghushchyan V, Sullivan PW: Physical activity in US adults with diabetes and at risk for developing diabetes, 2003. Diabetes care 2007; 30:203-209.

[5] Hunt CW: Technology and diabetes self-management: an integrative review. World J Diabetes 2015; 6:225-233.

[6] Sanders JP, Loveday A, Pearson N, Edwardson C, Yates T, Biddle SJ, Esliger DW: Devices for self-monitoring sedentary time or physical activity: a scoping review. JIMIR 2016; 18:e90.

[7] Shah VN, Garg SK: Managing diabetes in the digital age. Clin Diabetes Endocrinol 2015; 1:16-23.

[8] Schoeppe S, Alley S, Van Lippevelde W, Bray NA, Williams SL, Duncan MJ, Vandelanotte C: Efficacy of interventions that use apps to improve diet, physical activity and sedentary behaviour: a systematic review. Int J Behav Nutr Phys Act 2016; 13:127-153.

[9] Bonoto BC, de Araújo VE, Godói IP, de Lemos LLP, Godman $B$, Bennie M, Diniz LM, Junior AAG: Efficacy of mobile apps to support the care of patients with diabetes mellitus: a systematic review and meta-analysis of randomized controlled trials. JMIR Mhealth Uhealth 2017; 5:e4.
[10] Georgsson M, Staggers N, Weir C: A modified user-oriented heuristic evaluation of a mobile health system for diabetes self-management support. Comput Inform Nurs 2016; 34:7784.

[11] Hussain A, Mkpojiogu EO, Kamal FM: Eliciting user satisfying requirements for an e-health awareness system using kano model. Proceedings of the 14th International Conference On Applied Computer And Applied Computational Science (ACACOS'15), Kuala Lumpur: 2015. pp.156-165.

[12] Veazie S, Winchell K, Gilbert J, Paynter R, Ivlev I, Eden K, Nussbaum K, Weiskopf N, Guise J-M, Helfand M. Mobile applications for self-management of diabetes. J Gen Intern Med 2018; 33:1167-1176.

[13] Årsand E, Muzny M, Bradway M, Muzik J, Hartvigsen G: Performance of the first combined smartwatch and smartphone diabetes diary application study. J Diabetes Sci Technol 2015; 9:556-563.

[14] Reeder B, David A: Health at hand: a systematic review of smart watch uses for health and wellness. J Biomed Inform X 2016; 63:269-276.

[15] Dix, A. J., Finlay, J., Abowd, G. D., Beale, R. Human-computer interaction. 3th ed. London: Pearson Education; 2003.

[16] Bevan $\mathrm{N}$ : International standards for $\mathrm{HCl}$ and usability. Int J Hum Comput Stud 2001; 55:533-552.

[17] Zapata BC, Fernández-Alemán JL, Idri A, Toval A: Empirical studies on usability of mHealth apps: a systematic literature review. J Med Syst 2015; 39:1-19.

[18] Roche N, Scheuch G, Pritchard JN, Nopitsch-Mai C, Lakhani DA, Saluja B, Jamieson J, Dundon A, Wallace R, Holmes S: Patient focus and regulatory considerations for inhalation device design: report from the 2015 IPAC-RS/ISAM workshop. J Aerosol Med Pulm Drug Deliv 2017; 30:1-13.

[19] Coursaris CK, Kim DJ: A meta-analytical review of empirical mobile usability studies. J Usability Stud 2011; 6:117-171.

[20] Broderick J, Devine T, Langhans E, Lemerise AJ, Lier S, Harris L. Designing health literate mobile apps. NAM (serial online) 2014 Jan (cited 2019 June 5):1(1): (12 screens). Available from: URL: http:/ www.health.gov/communication/literacy/BPHHealthLiterateApps.pdf.

[21] Brown III W, Yen P-Y, Rojas M, Schnall R: Assessment of the Health IT Usability Evaluation Model (Health-ITUEM) for evaluating mobile health (mHealth) technology. J Biomed Inform X 2013; 46:1080-1087.

[22] Wang JB, Cataldo JK, Ayala GX, Natarajan L, Cadmus-Bertram LA, White MM, Madanat H, Nichols JF, Pierce JP: Mobile and wearable device features that matter in promoting physical activity. J Mob Technol Med 2016; 5:2-11.

[23] Brooke J: SUS: a retrospective. J Usability Stud 2013; 8:29-40.

[24] Brooke, J., SUS: A "quick and dirty" usability scale". Jordan, P. W., Thomas, B. A. Weerdmeester and McClelland editors. In Usability evaluation in industry, London: Taylor \& Francis; 1996.p.189-194.

[25] Demirkol D, Şeneler Ç: A Turkish Translation of the System Usability Scale: The SUS-TR. Usak Univ J Soc Sci 2018; 11:237253.

[26] Kortum PT, Bangor A: Usability ratings for everyday products measured with the System Usability Scale. Int J Hum Comput Interact 2013; 29:67-76.

[27] Taşdelen B, Kanik EA: The correct usage and reporting of biostatistical techniques in health researches. Mersin Univ J Health Sci 2009; 2:1-13. 
[28] Bangor A, Kortum P, Miller J: Determining what individual SUS scores mean: Adding an adjective rating scale. J Usability Stud 2009; 4:114-123.

[29] Patel S, Park H, Bonato P, Chan L, Rodgers M: A review of wearable sensors and systems with application in rehabilitation. J Neuroeng Rehabil 2012; 9:21-37.

[30] Nguyen NH, Hadgraft NT, Moore MM, Rosenberg DE, Lynch C, Reeves MM, Lynch BM: A qualitative evaluation of breast cancer survivors' acceptance of and preferences for consumer wearable technology activity trackers. Support Care in Cancer 2017; 25:3375-3384.

[31] Zahra, F., Hussain, A., and Mohd, H. Usability factors of mobile health application for chronic diseases, Proceedings of the 4th International Conference on Applied Science and Technology; 2016 May 29-30; Qingdao, China; New York: USA; 2016.
[32] Krebs P, Duncan DT: Health app use among US mobile phone owners: a national survey. JMIR Mhealth Uhealth 2015; 3:e101.

[33] El-Gayar O, Timsina P, Nawar N, Eid W: Mobile applications for diabetes self-management: status and potential. J Diabetes Sci Technol 2013; 7:247-262.

[34] Higgins JP: Smartphone applications for patients' health and fitness. Am J Med 2016; 129:11-19.

[35] Garcia-Zapirain B, de la Torre Diez I, Sainz de Abajo B, LópezCoronado M: Development, technical, and user evaluation of a web mobile application for self-control of diabetes. Telemed J E Health 2016; 22:778-785.

[36] Ridgers ND, Timperio A, Brown H, Ball K, Macfarlane S, Lai SK, Richards K, Mackintosh KA, McNarry MA, Foster M: Wearable activity tracker use among Australian adolescents: usability and acceptability study. JMIR Mhealth Uhealth 2018; 6:e86. 